\title{
Nuevos métodos en la educación artística. Experiencias docentes con MeTaEducArte (Método para Talleres de Educación desde el Arte). Taller: Danzando mis emociones, el cuerpo como herramienta artística
}

\author{
Cristina Moreno PABÓN \\ U. Autónoma de Madrid
}

\section{Resumen:}

MeTaEducArte, es la metodología usada en el diseño y desarrollo de este taller teórico-práctico. Esta nueva metodología para talleres de educación artística, utiliza recursos de métodos de enseñanza, como: el método MUPAI (Museo Pedagógico de Arte Infantil), especializado en talleres de arte contemporáneo en educación infantil y primaria; Aprendizaje Autónomo Motivador y Creativo; Aprendizaje Cooperativo; o Aprendizaje Basado en Problemas. El principal objetivo de MeTa EducArte, es la educación integral desde el arte, que incluya conocimientos, experimentación y estudio de los cambios de comportamiento emocional, mientras aprendemos de forma empírica, Cristina Moreno (2012), Cristina Moreno (2013).

En el taller "Danzando mis emociones, el cuerpo como herramienta artística", diseñado con este método, tendremos una válvula para oxigenarnos y sentirnos mejor, física, mental y emocionalmente. Cada artista-alumno, encontrará su propio lenguaje corporal para dibujar y crear en el espacio; trabajará la identidad y utilizará el arte como terapia. Como todos los talleres de MeTa EducArte, fomenta el aprendizaje autónomo, la capacidad de análisis, el razonamiento, el trabajo con la identidad y el espíritu crítico.

Con el soporte de las TIC, se proyectan imágenes de arte contemporáneo y de la propia cultura visual de los participantes para ilustrar los conceptos.

Se utilizará el método informativo y demostrativo, haciendo una breve descripción y demostración de las distintas técnicas y su uso, como medio expresivo y sanador. Una vez hecha la demostración, se procederá a la parte práctica, donde cada alumno desarrollará una o varias danzas expresando distintos sentimientos. Se utilizará también el método interactivo (demostrativo-práctico).

La recogida de datos para el estudio cuantitativo y cualitativo de los resultados obtenidos, se efectúa durante el taller. Este estudio recoge también la evaluación de satisfacción y el aprendizaje a través de él. Cristina Moreno Pabón (2012), Cristina Moreno Pabón (2013).

Los materiales usados en este taller son: Nuestro cuerpo, emociones, mucha creatividad, ganas de compartir y divertirse en todo momento.

Mediante dinámicas de diverso tipo, incluidas en el taller, los alumnos reflexionan y adquieren las competencias curriculares sobre danza, técnicas de relajación y expresión corporal. Después de interiorizaciones individuales, se realizan danzas tanto individuales como en grupo, expresando lo que sentimos: Al finalizar compartimos y evaluamos entre todos lo expresado y sentido desde la danza.

Palabras Clave: MeTaEducArte; talleres educación artística; emociones; danza.

\section{Referencia normalizada:}

Moreno Pabón, C. (2014): Nuevos métodos en la educación artística. Experiencias docentes con MeTaEducArte (Método para talleres de educación desde el arte). Taller danzando mis emociones, el cuerpo como herramienta artística. Historia y Comunicación Social. Vol. 19. Núm. Especial Febrero. Págs. 145-159. 


\section{MeTaEducArte: Método para Talleres de Educación desde el Arte.}

\subsection{Aspectos generales; principales objetivos.}

Como Educadora Artística mi "MeTa", es que mis alumnos desde el Arte y sus técnicas, disfruten, aprendan y se comprometan con el estilo de enseñanza que defiende el método por mi diseñado, para la educación artística. Repensando lo que quería transmitir con él, me surgió el término "MeTaEducArte", que además de dar nombre, da sentido, a este Método para Talleres de Educación desde el Arte.

Estos talleres sirven para todo tipo de alumnado, pero especialmente pretenden ser herramientas o instrumentos, para los alumnos, futuros docentes de Educación Infantil y de Primaria. Estos demandan una enseñanza personalizada, activa, atractiva y cercana a su propio lenguaje. Necesitan ver la utilidad y la oportunidad de la aplicación de lo aprendido inmediatamente; en su período de Prácticas, en los centros educativos asignados. El objetivo es que ellos aprendan, se diviertan y se identifiquen con este tipo de enseñanza. Desde el convencimiento y la experimentación empática, podrán llevar esta metodológica e ideología a sus aulas, para educar desde el arte y la emoción. Este método trabaja la identidad, emociones y sentimientos. Si los alumnos lo integran en su enseñanza, ayudarán a su vez a sus alumnos a encontrar su identidad y desarrollarla.

El principal objetivo de MeTaEducArte, además de los objetivos implícitos en el método, es la educación integral, que incluya conocimientos, experimentación y estudio de los cambios de comportamiento emocional, mientras aprendemos.

La metodología usada en el diseño y desarrollo de estos talleres teórico-práctico, está basada en los nuevos métodos de enseñanza, como: AAMC, AC y ABP. Estas metodologías han sido utilizadas en conjunción con el método MUPAI.

El método MUPAI incluye arte contemporáneo y como yo, también defiende la "educación artística" y no las manualidades, en la enseñanza infantil y primaria. María Acaso (2006). Utiliza imágenes visuales que los niños podrán identificar y que pueden encontrar en su entorno. Muchas están sacadas de medios publicitarios, revistas, libros y películas, relacionadas con su propio lenguaje visual (María Acaso, 2009. Pág. 21-47).

MeTaEducArte incluye el arte contemporáneo, como medio de expresión artística para cada alumno-artista. A través del arte en sus distintas facetas podemos encontrar una válvula para oxigenarnos y sentirnos mejor, física, mental y emocionalmente. Cada artista, al igual que cada alumno, encontrará su propio lenguaje dentro del arte, para encontrar su propia identidad.

Este método cree en la educación artística y el arte como terapia, considerando el arte y sus formas de expresión, un camino para construir la identidad integral del alumno. 
Los currículum de las asignaturas que imparto para los alumnos de Grado en Educación Infantil y Primaria, han sido adaptados a este tipo de enseñanza a través de talleres, con un currículum postmoderno, Arthur Efland (2003). He apostado por la capacidad creadora e imaginativa de los alumnos, considerándolos artistas; en pocos años, llevarán esta forma de ver y enseñar la educación artística a sus aulas.

Los talleres teórico-prácticos de arte contemporáneo MeTaEducArte., incorporan como soporte pedagógico, las nuevas tecnologías audiovisuales TIC. Un libro fundamental y de consulta realmente útil, para los temas relacionados con las TIC en la enseñanza, es el de la docente universitaria y artista, Ángeles Saura (2011). En el podemos encontrar gran cantidad de referencias y documentación muy atractiva tanto para el profesorado como para los alumnos.

El método de MeTaEducArte fomenta el aprendizaje autónomo, la motivación en el aprendizaje, el trabajo cooperativo en grupo y propone el aprendizaje basado en problemas. Se pretende que el alumno de forma empírica, saque sus propias conclusiones. Esta forma de aprender, estimula el lado más creativo del alumno, ayudándole a ser más autónomo en su aprendizaje y fomentándole la capacidad de análisis, razonamiento y el espíritu crítico.

Desde esta perspectiva, van a adquirir los conocimientos y competencias curriculares, sobre el arte, sus aplicaciones, sus técnicas y la forma de enseñarlo. Tendencias educativas como la Educación Artística basada en la Cultura Visual, María Acaso (2009), apuestan y reivindican el tema de la identidad como uno de los más importantes a tratar, Manuel Belver (2005). Mediante actividades de diverso tipo, incluidas en estos talleres, se busca que los participantes reflexionen sobre su propia identidad, Kerry Freedman (2006). Con los conocimientos adquiridos, se realizarán obras con distintas técnicas, que les harán sentirse creadores y artistas, Cristina Moreno Pabón (2012), Cristina Moreno Pabón (2013).

1.2 Aspectos competenciales.

\subsubsection{Objetivos competenciales}

- Obtención de conocimientos de la teoría del tema y la técnica, a través de la motivación y la creatividad del alumno.

- Conocer los conceptos propios del tema tratado en el taller.

- Saber realizar las técnicas propias del tema objeto del taller

- Adquirir competencias de forma empírica y divertida.

\subsubsection{Objetivos formativos y actitudinales:}

- Desarrollar la capacidad de trabajo en equipo.

- Desarrollar la capacidad creativa e imaginativa. 
- Desarrollar la capacidad de resolución de problemas.

- Desarrollar la capacidad crítica.

- Desarrollar la capacidad de expresarse en público y dinamizar un grupo de alumnos.

- Adquirir capacidad para la autoevaluación del propio aprendizaje.

- Adquirir capacidad para realizar una evaluación más justa y crítica.

- Desarrollar la autonomía en el aprendizaje

\subsubsection{Metodología del Aprendizaje:}

- Basado en el arte contemporáneo.

- Basado en las técnicas y estilos que usan los artistas.

- Basado en la educación artística y no en las manualidades.

- Utilización de las TIC como medio docente.

- Utilización de imágenes de arte contemporáneo y de la cultura visual de los alumnos.

- Basado en la educación integral de la personalidad, uniendo conocimientos, emociones y sentimientos.

- Basado en el trabajo y desarrollo de la identidad del alumno.

- Basado en la cooperación en equipo.

- Iniciado por problemas, planteando preguntas y mostrando imágenes, que estimulen la intriga y el debate.

- Basado en rotación de roles en los equipos de trabajo.

- Aprender haciendo: a expresarse en público.

- Aprender haciendo: a dinamizar un grupo de alumnos (dinámicas de grupo).

- Aprender a través del seguimiento de lo escuchado o leído (técnica del puzle para la teoría)

- Aprender a través de errores propios y correcciones; aprendemos cuando nos equivocamos y repetimos.

- Aprender desde la práctica y la solución de problemas o casos planteados (estudios de casos).

- Construcción propia a partir de situaciones / materiales.

- Repetición de lo recibido. En casa, cada uno hace un trabajo, que compartirá en clase 
- Aprendizaje basado en la autoevaluación de lo aprendido.

\subsubsection{Objetivos de Docencia}

- Centrada en el aprendiz. El docente facilita, orienta y dinamiza; comparte experiencia, hace de moderador y provoca estimulando al grupo.

- Centrada en el docente. Éste muestra y conduce (pero deja hacer de forma autónoma)

\subsubsection{Evaluación}

- Repetición de lo recibido. Evaluación continúa.

- Resolución de nuevos casos o problemas o prácticas más complejas.

- Autoevaluaciones de lo aprendido mediante cuestionarios y preguntas.

- Evaluación del taller y de sus posibilidades de aplicación

1.3 Contenidos y desarrollo de la metodología.

\subsubsection{Dinámica de grupo}

El taller comienza con una dinámica de grupo para romper el hielo, que variará dependiendo del grupo, si es un taller aislado o está dentro de un proyecto o asignatura. Las dinámicas no pueden ser las mismas los primeros días de clase, que en la mitad del curso o al final. Lógicamente los objetivos cambian.

\subsubsection{El desarrollo del taller}

En su primera fase, el taller comienza, con una diapositiva con la pregunta que sirve de detonante para el grupo y que les hace reflexionar entrando en los contenidos del taller. Tras las primeras impresiones y una vez roto el hielo, los alumnos mantendrán una actitud de colaboración, interactuando siempre que lo deseen; de esta forma tememos garantizado el interés en la parte teórica, que se mezcla con la práctica.

$\mathrm{Al}$ estar enfocado para infantil y primaria, se recomienda a los alumnos de Formación del Profesorado, comenzar el taller narrando una historia que se relacione con el tema a tratar y que "enganche" a los niños o adolescentes.

Se utilizará el método informativo y demostrativo, haciendo una breve descripción y demostración de los distintos materiales y su uso, como medio expresivo y sanador. Aquí se puede utilizar el estudio de un caso.

El método es también interactivo (demostrativo-práctico). Se enseñarán, los distintos materiales que vamos a usar y cómo utilizarlos. 
Una vez hecha la demostración, y vista la teoría, se procederá a la parte práctica, donde cada alumno hará uno o varias composiciones artísticas, utilizando la técnica objeto del tema. Experimentarán la técnica aprendida de forma libre, reflexionando sobre cuáles son los sentimientos evocados y materializándolo en forma de creación artística.

La práctica termina con una encuesta individual, sobre cómo nos hemos sentido. Mostraremos nuestras obras al grupo y expresaremos las experiencias vividas, compartiéndolas con los compañeros. Todos aprendemos de los demás.

Una vez aprendida la técnica y con mayor destreza, es hora de trabajar en grupo y realizar una obra común entre los cuatro miembros de cada grupo. Aquí es bueno romper los grupos formales y hacer grupos con distintos miembros. Este trabajo fomenta la participación, la comprensión y la compenetración.

\subsubsection{Autoevaluaciones de lo aprendido, mediante cuestionarios y preguntas}

La dinámica de evaluación, debe variar de un taller a otro. El factor sorpresa es importante y resulta más divertido. Utilizaremos preguntas lanzadas al grupo o directamente a un alumno para debatir, así como cuestionarios, o preguntas cortas escritas.

\subsubsection{Conclusiones}

Al finalizar las prácticas, como conclusión, analizaremos en conjunto los objetivos del taller, los procedimientos empleados, lo que hemos aprendido: conocimientos, habilidades actitudes, etc. Entre todos realizaremos una lista visible para el grupo.

\subsubsection{Fase de evaluación del taller:}

Para terminar, se hace una autoevaluación del taller. Es muy importante saber la opinión de cada niño o alumno, sobre lo que ha aprendido, si le ha resultado atractivo y si algo se podría mejorar. Todo esto queda recogido en forma de test, donde se valoran cuatro tipos de datos:

- Datos relativos al nivel de satisfacción general con el taller.

- Datos relativos al nivel de aprendizaje (estudiantes y profesores).

- Datos relativos al nivel de satisfacción respecto a los guías/educadores.

- Datos relativos al nivel de satisfacción con la forma de exposición.

- Cristina Moreno Pabón (2012), Cristina Moreno Pabón (2013) 


\section{Taller: Danzando mis emociones, el cuerpo como herramienta artística.}

Fragmento de Poesía a Clara Bueno o Arkana, https://sites.google.com/site/ danzakarana:

Cuando danzas, el tiempo se olvida de vivir y se desmaya, entonces, la eternidad se asoma por las ventanas de tu Alma y no resulta posible, ya, pronunciar ninguna palabra, pues el reino del corazón se expande y se engalana con innumerables recién florecidas flores variadas. Lo relativo deja caer sus máscaras. Ya no importa nada. Sólo lo trascendente. En ti, se posan todas las miradas, abstraidas, bendita y fulgurante danzarina sagrada. Despiertas una dormida, melancólica y honda añoranza, $y$, en los luceros, brotan perladas y candorosas lágrimas, como si quisiesen regar el vergel de las flores del Alma. Algo muere y algo nace; la razón, a explicarlo, no alcanza. Pues tú las evocas, con tu arte, aparecen difuminadas, en la mente, imágenes de antiguas culturas mediterráneas, trayendo al presente lo que fuiste antaño, vinculada, muchas veces, durante milenios, en tus vidas pasadas, a templos y Escuelas de misterios y a espirituales danzas. La diosa comienza a inundarlo todo con su amor que embriaga, y los espíritus vibran dentro de los cuerpos, sin pausa. ¿Qué misteriosa fuerza transfiguradora posees, maga? El poder de la música y todo aquello que tú emanas a un etéreo mundo de éxtasis sin fin, me traslada, y no quiero regresar. Esta muerte en vida, me mata, y me resucita, pero, aunque a mi cuerpo nunca me reintegrara, sigue; no pares; no dejes de danzar, adorable y divina Clara. (Castellar Fratello, 2013)

Clara-Arkana nos explica en que consiste la metodología diseñada por ella: Danza Karana, danza para el Alama:

LA LUZ LLEGA CUANDO TU LA DANZAS" Cuando te alineas, activas todos tus chacras, empleas la geometría sagrada establecida en tu cuerpo, respiras penetrando en la polaridad del movimiento en un ritmo que esta en la música en tu cuerpo y en el Universo. Unido a la entrega y a la conciencia que hay dentro de estos vórtices energéticos, tu Alma vuela a hacia una entrega que te lleva a estar en el vació en esa parte de la molécula que es un $99 \%$ y es vació es TODO. Ya no hay peso, ya no hay mente Fluyes con las Alas del Alma, te llenas de Luz y el espíritu entra en ti manifestándose en Tu Danza. Eso es mi experiencia con lo que llamo ahora llamo danza cuántica, Danza Karana del Alma y de la Ttransformación. (Clara Bueno-Arkana, 2013) https://sites.google.com/site/danzakarana.

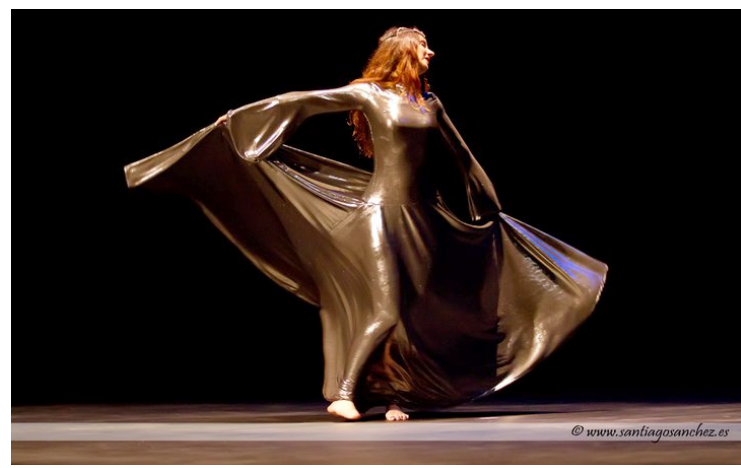

Imagen 1. Clara Bueno- Arkana durante uno de sus espectáculos bailando danza Karana 


\subsection{Desarrollo del taller}

La danza que nace del sentimiento y la emoción, no necesita estructura predeterminada, que la encasille, nos ofrece la oportunidad de expresarnos con plena libertar. Estoy completamente de acuerdo con la forma de sentir y danzar de Clara Bueno, en ella me inspire para el diseño de del taller "Danzando mis emociones, el cuerpo como herramienta artística". Este taller siguiendo la metodología MeTa EducArte, nos ayudará a sentirnos mejor, física, mental y emocionalmente. Cada artista-alumno, trabajará con su identidad, utilizando la danza como terapia, encontrará su propio lenguaje corporal para dibujar y crear en el espacio. Como todos los talleres de MeTa EducArte, fomenta el aprendizaje autónomo, la capacidad de análisis, el razonamiento y el espíritu crítico.

Se utilizará el método informativo y demostrativo, haciendo una breve descripción y demostración de las distintas técnicas y su uso, como medio expresivo y sanador.

Una vez hecha la demostración, se procederá a la parte práctica, donde cada alumno desarrollará una o varias danzas expresando distintos sentimientos y narrando su historia personal. También se crearán grupos de cuatro o cinco alumnos que crearán historias para danzarlas a todo el grupo.

Se utilizará también el método interactivo (demostrativo-práctico).

La recogida de datos para el estudio cuantitativo y cualitativo de los resultados obtenidos, se efectúa durante el taller. Este estudio recoge también la evaluación de satisfacción y el aprendizaje a través de él.

Los materiales usados en este taller son: Nuestro cuerpo, emociones, mucha creatividad, ganas de compartir y divertirse en todo momento.

Mediante dinámicas de diverso tipo, incluidas en el taller, los alumnos reflexionan y adquieren las competencias curriculares sobre danza, técnicas de relajación y expresión corporal. Después de interiorizaciones individuales, se realizan danzas tanto individuales como en grupo, expresando lo que sienten con ese proceso.

Al finalizar compartimos y evaluamos entre todos lo expresado y sentido desde la danza.

\subsection{Metas y contenidos.}

Además de los objetivos descritos e implícitos en el método de enseñanza para el taller, el principal objetivo del taller "Danzando mis emociones, el cuerpo como herramienta artística", es la experimentación y estudio de los cambios de comportamiento emocional, que la danza expresada desde la emoción y el sentir tiene sobre la conducta y estado de ánimo en el alumno.

Otro de los objetivos más relevantes del taller didáctico, es que los alumnos participantes reflexionen sobre su propia identidad y los elementos que la constituyen, adquiriendo conocimientos de forma empírica sobre este forma de danzar. 
El material principal con el que trabajar a lo largo de esta actividad es el propio cuerpo, la creatividad mental y emocional para pintar, dibujar o esculpir en el espacio con la danza. En la parte teórica se abordan nociones sobre la teoría de este tipo de danza. La teoría incorpora, arte contemporáneo y productos visuales de distinta índole. Con los conocimientos adquiridos se realizarán danzas individuales y colectivas.

2.3 Aspectos competenciales.

\subsubsection{Objetivos competenciales}

- Obtención de conocimientos en diversas técnicas la danza, relajación y expresión corporal a través de la motivación y la creatividad del alumno

- Saber los conceptos principales de la danza, la relajación y la expresión corporal.

- Saber hacer las técnicas de danza, relajación y expresión corporal aprendidas en el taller, expresando con el cuerpo emociones y sentimientos.

- Adquisición de las competencias de forma empírica y divertida.

\subsubsection{Objetivos formativos y actitudinales:}

Ver punto 1.2.2.

\subsubsection{Metodología del Aprendizaje:}

Ver punto 1.2.3.

\subsubsection{Objetivos de Docencia:}

Ver punto 1.2.4.

\subsection{Evaluación}

Ver punto 1.2.5.

2.4.1 Contenidos y desarrollo de la metodología.

\subsubsection{Dinámica de grupo : Danzan quién es y cómo se siente tu compañero}

Esta dinámica, propuesta para romper el hielo, puede variar dependiendo del grupo, si es un taller aislado o está dentro de un proyecto o asignatura.

Hablamos, con el compañero que está a nuestro lado; en un tiempo aproximado de 5 minutos lo conozco mejor, su nombre, sus gustos, sus estudios, etc... 
¿Quién mejor que nosotros para presentar a nuestro nuevo amigo? Ahora lo conocemos mejor y él me conoce a mí. Así, desde la expresión corporal y verbal presentamos a nuestro nuevo amigo al grupo.

\subsubsection{El desarrollo del taller}

\subsubsection{Materiales}

- Ropa cómoda que nos permita movernos con libertad.

- Ordenador, altavoces y cañón de luz, para las presentaciones y la música.

- Si se hace en el exterior, se utilizará proyector y pantalla apropiada.

- Distintos tipos de música, relajante, movida, lenta, impactante, etc.

- Cámara de video y/o fotográfica.

- Lógicamente nuestro cuerpo, emociones, mucha creatividad, ganas de compartir y divertirse en todo momento.

\subsubsection{Tareas a realizar:}

- Realización de al menos una técnicas de relajación (variaran dependiendo del grupo).

- Realización de al menos tres danzas libres, variando el tipo de música, expresando lo que sentimos, dibujando en el espacio los colores de nuestra mente y poniendo especial interés en conectar la danza con nuestras emociones.

- En grupos de cuatro o cinco alumnos, componer una danza libre, que narraran danzando al resto de compañeros.

- Grabación de las actuaciones de los grupos con videos y fotos, para poder comentar con posterioridad los trabajos realizados entre todos.

\subsubsection{Temporalización}

El tiempo óptimo para la realización del taller completo para los alumnos de infantil y primaria, es de 120 a 180 minutos.

2.4.3.4 Metodología: Talleres de Educación desde el Arte, MeTaEducArte 


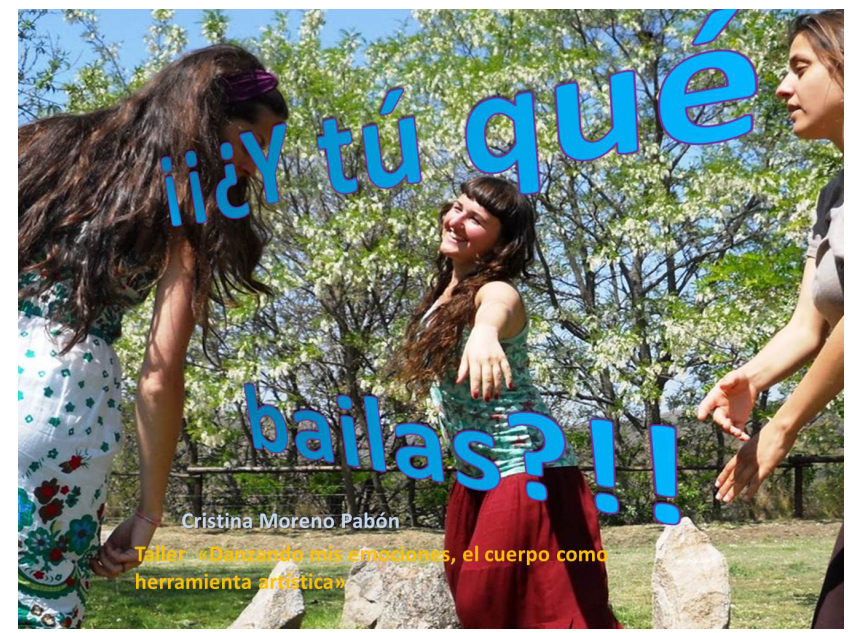

Imagen 2: Diapositiva detonante del tallerii¿Y tu qué bailas?!!

Comenzamos el taller con una diapositiva con la pregunta que sirve de detonante para el grupo, que les hace reflexionar entrando en los contenidos del taller.

Para este taller la pregunta detonante es. ii¿Y tu qué bailas?!! (Ver imagen 2). El taller teórico-práctico, combina conceptos con preguntas abiertas a los participantes, manteniendo así el interés del alumnado.

Con la incorporación de imágenes de arte contemporáneo y de la propia cultura visual de los participantes para ilustrar los conceptos, se pretende que lo aprendido en el taller no se quede en él, sino que salga con ellos y lo puedan aplicar en su día a día. Las Tic son medio utilizado para apoyar las explicaciones teóricas.

Este taller está enfocado principalmente alumnos de infantil y primaria; así recomiendo a los alumnos de Formación del Profesorado, introducir el taller narrando una historia que esté relacionada con la danza y la expresión corporal, y que ayude a "enganchar" a los niños o adolescentes. Lógicamente esta historia variará dependiendo del grupo al que va dirigido el taller.

Con base en los métodos de enseñanza AAMC, AC, ABP y el método MUPAI, MeTaEducArte utiliza el método informativo y demostrativo, haciendo una breve descripción y demostración de los distintos materiales y su uso, como medio expresivo y sanador.

Una vez hecha la demostración, se procederá a la parte práctica. Comenzamos con una relajación con todo el grupo, invitando a los alumnos a conectar con sus sentimientos, que visualizarán como los expresarían en el espacio. Cada alumno hará uno o varias danzas libres expresando distintos sentimientos y narrando sus historias personales.

Se utilizará también el método interactivo (demostrativo-práctico). 
La recogida de datos para el estudio cuantitativo y cualitativo de los resultados obtenidos, se hace durante el taller.

El taller se desarrolla en varias fases; cada una de ellas dividida en dos partes:

- Una parte teórica, como soporte para la explicación de la teoría de las diversas técnicas de la danza, relajación, expresión corporal y la creación artística utilizando el cuerpo como herramienta.

- Una parte práctica, donde el alumno tendrá la oportunidad de practicar y experimentar la técnica, participando activamente, expresando sus emociones y sentimientos.

Al finalizar cada fase teórico-practica, se termina con unos minutos de reflexión para compartir la experiencia con todo el grupo.

En la última fase del taller, haremos grupos de cuatro o cinco alumnos, que harán un trabajo común. Este trabajo, fomenta la participación en grupo, la comprensión, la compenetración, la integración y la empatía.

Para terminar, se hace una autoevaluación del taller entre todos de lo aprendido en este. Se pueden hacer preguntas concretas o dejar que ellos hagan una reflexión y lancen preguntas a los compañeros. Los alumnos sacarán sus propias conclusiones.

2.4.4 Autoevaluaciones de lo aprendido, mediante cuestionarios y preguntas

Ver punto 1.3.3.

\subsubsection{Conclusiones}

Ver punto 1.3.4. Si el número de alumnos no es numeroso, se puede usar una dinámica de grupo, como la del ovillo, "estamos enredados: El dinamizador del grupo lanza un ovillo de lana (quedándose con el extremo) a cualquier compañero y se presenta dando algunos datos fáciles de recordar sobre él, a todo el grupo. El receptor del ovillo hace lo mismo, se presenta y quedándose con el hilo, lanza nuevamente el ovillo, a otro compañero al azar. Al final, el dinamizador tendrá el ovillo de regreso y estaremos todos "enredados". Conociéndonos mejor.

Para deshacer la red, el dinamizador lanza el ovillo al compañero que se lo envió y tiene que presentarlo, contando lo que él nos había dicho con anterioridad. Esto se repite y al final, al terminar la dinámica, tendrá el ovillo nuevamente en sus manos.

Esta dinámica, la podemos utilizar, al principio para presentarnos y al finalizar, para sacar conclusiones de lo que más nos ha gustado del taller y lo que hemos aprendido. En cualquier, caso siempre repetimos nuestros nombres, lo que hace que el grupo se afiance" (Moreno Pabón, 2012. Pág. 88), (Moreno Pabón, 2013. Pág. 345 ). 


\subsubsection{Fase de evaluación del taller:}

Ver punto 1.3.5

\section{Conclusiones sobre la experiencia docente del taller: Danzando mis emocio- nes, el cuerpo como herramienta artística.}

La experiencia durante los dos años que llevo impartiendo este taller, ha sido muy satisfactoria, cumpliéndose todas las expectativas y objetivos de los que parte el taller (Ver puntos 1.2.1. y 1.2.2.). Lógicamente los contenidos y dinámicas del taller, se han ido adaptando a las necesidades del grupo.

Cuando he impartido este taller en museos con adolescentes o niños, los resultados han sido excelentes. Como ejemplo, vemos a continuación las puntuaciones cuantitativas, de un taller realizado en el museo Teixeira Lopes en Mirandela, Portugal. Veinticinco preadolescentes entre diez y doce años, hacen la siguiente evaluación del taller, puntuando del 1 al 10:

- ¿Te ha gustado el taller? $\mathbf{9 , 8}$

- ¿Te gustaría volver a hacer una actividad en nuestro museo? 9,7

- ¿Te han gustado los monitores? $\mathbf{1 0}$

- ¿Te ha gustado el Museo? 9,8

- ¿Y la presentación en Power Point? (su explicación) 10

- ¿Crees que hay tiempo suficiente para hacer las actividades? 8

En los talleres con alumnos de formación del profesorado, disfrutaron aprendiendo como si de sus propios alumnos se tratara, y lo principal es que han visto la posibilidad de llevar este taller a su propia docencia. De hecho, durante sus prácticas en los colegios, pudieron probar alguna de estas experiencias, grabando los resultados en video.

Durante las exposiciones de los trabajos y las experiencias realizados en la clase con todo el grupo, han aprendido diferentes formas de resolver un mismo planteamiento. Esto ha supuesto un enriquecimiento para todos, incluyéndome a mí. Es de resaltar la creatividad que pueden desarrollar, siendo esto un gran estímulo para ellos. 


\section{Bibliografía}

\subsection{Libros:}

ACASO, María (2006): La educación artística no son manualidades. Catarata. Madrid.

ACASO, María (2009): El lenguaje visual. Paidós. Barcelona.

BELVER, Manuel y ULLÁN Ana (2007): La creatividad a través del juego. Amarú. Salamanca.

BELVER, Manuel, ACASO, María. y MERODIO, Isabel (2005): Arte Infantil y Cultura Visual. Eneida. Madrid.

COOPER, James, PRESCOTT, Susan, COOK, Lenora, SMITH, Lyle and MUECK, Randall and CUSEO, Joseph (1990): Cooperative Learning and College Instruction. State University Foundation, Long Beach, CA. California.

EFLAND, Arthur, FREEDMAN, Kerry y STHUR, Patricia. (2003): La educación en el arte posmoderno. Paidós. Barcelona.

FREEDMAN, Kerry. (2006): Enseñando cultura visual. Octaedro. Barcelona.

JOHNSON, David; JOHNSON, Roger and SMITH, Karl (1991): Cooperative Learning: Increasing College Faculty Instructional Productivity. Ashe-Eric Higher Education Report No. 4, George Washington University. Washington.

MORENO, Rafael. y MARTÍNEZ, Rafael (2008): El Aprendizaje Basado en Problemas en la Enseñanza Universitaria. Universidad Murcia. Murcia.

SAURA PERÉZ, Ángeles (2011): Innovación educativa con TIC en Educación Artística, Plástica y Visual. Líneas de investigación y estudios de casos. Mad S.L. Madrid.

4.2 Capítulos o artículos en libros o revistas en papel:

EFLAND, Arthur (2005): Infancia y cultura visual, en BELVER, Manuel, ACASO, María y MERODIO, Isabel: Arte Infantil y Cultura Visual. Eneida. Madrid. pp.

MORENO PABÓN, Cristina (2012): Proyecto de Innovación Docente MeTaEducArte (Método para Talleres de Educación desde el Arte). Nuevos métodos en la educación artística: talleres de arte contemporáneo en la educación primaria e infantil, en DE HARO DE SAN MATEO, Ma Verónica: Novedades Docentes en el EEES. Visión libros. Madrid.

MORENO PABÓN, Cristina (2013): MeTaEducArte (Método para Talleres de Educación desde el Arte). El arte contemporáneo como medio de expresión, en la Educación Infantil y Primaria con uso de TIC, en CASALS CARRO, María Jesus et al: Estudios sobre el Mensaje Periodístico. Universidad Complutense de Madrid. Madrid.

POZO, Juan y MATEOS, Mar. (2009): Aprender a aprender: hacia una gestión autónoma y meta-cognitiva del aprendizaje, en POZO, Juan y PÉREZ, María Puy: Psicología del aprendizaje universitario: la formación de competencias. Morata. Madrid. 
POZO, Juan y MONEREO, Carles. (2009): Introducción: La nueva cultura del aprendizaje universitario ¿o por que cambiar nuestras formas de enseñar y aprender?, en POZO, Juan y PÉREZ, María Puy: Psicología del aprendizaje universitario: la formación de competencias. Morata. Madrid.

4.3 Artículos en publicaciones web:

BUENO ARKANA, Clara (2013): Poesía a Clara Bueno. Danza Karana: La Luz llega cuando tú la danzas Disponible en: https://sites.google.com/site/danzakarana. Consultado el 15 de marzo de 2013.

CASTELAR FRATELLO, Víctor (2013): Poesía a Clara Bueno. Disponible en: https://sites.google.com/site/danzakarana. Consultado el 15 de marzo de 2013.

MORENO PABÓN, Cristina (2013): MeTaEducArte (Método para Talleres de Educación desde el Arte). El arte contemporáneo como medio de expresión, en la Educación Infantil y Primaria con uso de TIC, en CASALS CARRO, María Jesus et al: Estudios sobre el Mensaje Periodístico, Vol. 19. Disponible en: http:// revistas.ucm.es/index.php/ESMP/article/view/42041. 